\title{
Análisis espacial de la integración y dispersión urbana sobre los flujos vehiculares a Villavicencio por la vía antigua y la vía nueva a Bogotá (Colombia)'
}

Recepción: 30 de junio de 2021 - Evaluación: 8 de noviembre de 2021 • Aprobación: 29 de noviembre de 2021

\begin{abstract}
Resumen: Se realiza el análisis de la relación existente entre dos sectores urbanos de Villavicencio y su colindancia con la vía al Llano, particularmente los que permiten el acceso (salida y entrada) por la vía antigua (VA) y la vía nueva (vN) a la ciudad. Esto, desde procedimientos técnicos y algunos elementos referenciados en la sintaxis espacial (SE), mediante el uso de medidas topológicas y el análisis de lo que sucede en cada lugar. Se describen los procesos morfológicos urbanos reflejados en la cantidad de vías, intersecciones y áreas construidas que componen estos espacios urbanos y proveen un tipo de lenguaje que permite identificar algún tipo de patrón que explique, desde una parte de los elementos físicos de la ciudad, el grado de vínculo o aislamiento entre territorios urbanos con la periferia: un signo socioespacial. El uso de rangos de color como indicadores de la intensidad de integración en los mapas, así como elementos geométricos de la distribución de nodos e intersecciones, cantidad de líneas y nodos asociados a la distancia de las vías, entre otros, fundamentan el análisis realizado a cada sector, definen centralidades en cada uno y la correspondencia entre la jerarquización de las vías y los niveles de funcionalidad urbana. La expansión y la fragmentación en torno a la implantación de la vía son asumidas como fenómenos espaciales particulares que subyacen a la integración o dispersión social del sector.
\end{abstract}

Palabras claves: áreas urbanas, distribución geográfica, planeación urbana, sintaxis espacial, patrones residenciales, Villavicencio (Colombia).

Para citar: Romero Novoa, J. A. (2022). Análisis espacial de la integración y dispersión urbana sobre los flujos vehiculares a Villavicencio por la vía antigua y la vía nueva a Bogotá (Colombia). Perspectiva Geográfica, 27(1), 146-167. https://doi.org/10.19053/01233769.13086

El artículo se desarrolla a partir de la información obtenida en el año 2019, en la fase inicial de la investigación doctoral titulada "Ciudad bisagra: relación entre los regímenes de desarrollo y el proceso de configuración territorial de la ciudad de Villavicencio (Colombia), entre 1936 y 2019”, que el autor adelanta en el Doctorado en Estudios Territoriales de la Universidad de Caldas (Colombia), Grupo de Investigación Territorialidades y línea de investigación "Territorialización de las acciones y procesos de metropolización".

2

Magíster en Geografia de la Universidad Pedagógica y Tecnológica de Colombia, Universidad Santo Tomás, Villavicencio, Colombia. Correo: jorgeromero@usantotomas.edu.co. Orcid: http://orcid.org/0000-0003-4623-6409 


\title{
Spatial analysis of urban integration and dispersion on traffic flows to Villavicencio along the old road and the new road to Bogotá (Colombia)
}

\begin{abstract}
An analysis is made of the existing relationship between two urban sectors of Villavicencio and the road to the Llano, particularly those that allow access (exit and entrance) via the old road (OR) and the new road (NR) to the city. This, from technical procedures and some elements referenced in the spatial syntax (ss), through the use of topological measurements and the analysis of what happens in each place. Describing the urban morphological processes reflected in the number of roads, intersections and the built areas that conform these urban spaces and provide a kind of language that allows identifying some kind of pattern to explain, from a part of the physical elements of the city, the degree of connection or isolation between urban territories with the periphery: a socio-spatial sign. The use of color ranges as indicators of the intensity of integration in the maps, as well as geometric elements of the distribution of nodes and intersections, number of lines and nodes associated with the distance of the roads, among others, support the analysis of each sector, define focal points in each one and correspondence between the hierarchy of roads and the levels of urban functionality. The expansion and fragmentation around the implementation of the road are assumed as particular spatial phenomena that are behind the social integration or dispersion of the sector.
\end{abstract}

Keywords: urban areas, geographical distribution, urban planning, spatial syntax, residential patterns, $V_{i-}$ llavicencio (Colombia).

\section{Análise espacial da integração e dispersão urbana sobre os fluxos veiculares para Villavicencio pela estrada antiga e pela nova estrada para Bogotá (Colômbia)}

\begin{abstract}
Resumo: Realiza-se a análise da relação existente entre dois setores urbanos de Villavicencio e sua proximidade com a via ao Llano (à Planície colombiana), particularmente os que permitem o acesso (saída e entrada) pela via antiga (vA) e a via nova (vN) à cidade. Isto, desde procedimentos técnicos e alguns elementos referenciados na sintaxe espacial (sE), mediante o uso de medidas topológicas e a análise do que acontece em cada lugar. Descrevem-se os processos morfológicos urbanos refletidos na quantidade de vias, intersecções e áreas construídas que compõem estes espaços urbanos e proporcionam um tipo de linguagem que permite identificar algum tipo de padrão que explique, desde uma parte dos elementos físicos da cidade, o grau de ligação ou isolamento entre territórios urbanos com a periferia: um sinal socioespacial. A utilização de gamas de cores como indicadores da intensidade de integração nos mapas, bem como elementos geométricos da distribuição dos nós e intersecções, quantidade de linhas e nós associados à distância das vias, entre outros, fundamentam a análise realizada a cada setor, definem centralidades em cada um e correspondência entre a hierarquização das vias e os níveis de funcionalidade urbana. A expansão e a fragmentação em torno à implantação da via são assumidas como fenômenos espaciais particulares que estão subjacentes à integração ou dispersão social do setor.
\end{abstract}

Palavras-chaves: áreas urbanas, distribuição geográfica, planejamento urbano, sintaxe espacial, padrões residenciais, Villavicencio (Colômbia). 


\section{Introducción}

Los problemas territoriales que se producen en las ciudades colombianas representan un desafío para los análisis tradicionales centrados en la morfología de las dinámicas urbanas. Los estudios urbanos asociados al crecimiento de las ciudades dan cuenta en primera instancia del tamaño, la cantidad y la tipología de los elementos urbanos, y parten de una óptica cuantitativa y economicista que privilegia la información estructural (Bielza, 2011). En este sentido, la relación entre la ciudad y lo urbano $^{3}$ se soporta, esencialmente, en la distribución de los elementos, en la geometría de los asentamientos y en la cantidad de personas que conforman un asentamiento humano (Reynoso, 2010); sin embargo, esta información se simplifica en la representación geográfica y oculta las particularidades del sistema espacial mediante la homogeneización de las formas urbanas. Así, entonces, se requiere una aproximación analítica que incorpore la intensidad, la distribución y la multiplicidad de elementos que conforman el área urbana.

Los nuevos espacios urbanos que configuran la ciu$\operatorname{dad}^{4}$ proporcionan significados asociados al progreso económico y la administración estatal principalmente; simbolizan los intereses, concepciones y expectativas que orientan acciones para configurar el territorio como producto de un conjunto de relaciones que se dan entre la ciudad y su entorno (Aliste et al., 2015; Santos, 2000); y se expresan en múltiples aspectos del

3 A propósito de las ideas propuestas por Kevin Lynch (2008) y por Antoine Bailly (1979) sobre la imagen de la ciudad (para el primero) y la concepción urbana de ella (para el segundo), se define en el paisaje urbano el proceso mediante el cual se hace legible para diferentes individuos y se interviene por la experiencia colectiva. Las concepciones van más allá de la percepción, implican un juicio sobre lo que es la ciudad y una forma de abordarla/producirla.

4 Para efectos conceptuales, la relación existente entre lo urbano y la ciudad será "concebida como la unión indisociable de aquello que los romanos llamaban urbs (territorio físico de la ciudad) y civitas (comunidad de ciudadanos que la habitan), o todavía más como la pertenencia recíproca de una entidad espacial discreta y fija, y de una población" (Choay \& Urrieta 2009, p. 161). De tal manera que el lugar que ocupan las edificaciones, las vías, su expansión y su fragmentación, y todo elemento no humano, hacen parte de lo urbano, mientras que las dinámicas y sus procesos harán parte de la ciudad. entramado urbano como las vías, por ejemplo. Se trata de aquel conjunto de elementos no humanos que tienen capacidades intrínsecas de visibilizar, a través de su disposición y su correlación con otros elementos urbanos, su funcionalidad en el territorio (Latour, 2008; Lefebvre, 2013; Hernández, 2017).

Resulta interesante, entonces, considerar la circulación de seres humanos, bienes e información como flujos y la relación entre áreas urbanas con la periferia como diversas posibilidades de organización de su estructura (normalmente con límites difusos que no coinciden necesariamente con las formas areolares). Una red de relaciones sociales definidas por proyectos urbanísticos y procesos de expansión de la infraestructura dominante desde la planeación y la administración territorial (Monnet, 2013), y de vínculos que se producen por la articulación de territorios transformados por las vías ${ }^{5}$. De esta manera, resulta estratégico y determinante asociar proyectos de infraestructura con el crecimiento urbano acelerado (Rincón, 2016), la producción de nuevas articulaciones productivas con el aumento del tamaño poblacional (Corboz, 2004) y la localización de sectores perimetrales como producto de rutas comerciales de carga y pasajeros - caso de la vía Villavicencio a Bogotá-.

Así, el presente artículo busca, mediante la aplicación de los procedimientos y técnicas enmarcadas en la sintaxis espacial (SE), realizar un análisis espacial de la estructura urbana que rodea los flujos terrestres por la vía antigua (VA) y la vía nueva (VN), accesos de la vía Villavicencio-Bogotá, al identificar algún patrón que explique, por una parte, los elementos físicos de la ciudad y, por la otra, los signos de lo social (Hillier, 2007). Esto se entiende en la correlación espacial que subyace en las vías, sus intersecciones y su distribución; la disposición geométrica de estos elementos representa la integración, la dispersión y la fragmentación social

5 Como señala Contreras (2006), "las relaciones de poder [político-económico] en el paisaje urbano [son] un medio de expresión". 
del sector. A partir de ello, se pueden hacer algunas afirmaciones relacionadas con la distribución de los elementos (nodos y líneas) y su expresión como ideas de integración y dispersión urbana producto de la comparación geográfica en dos lugares de Villavicencio relacionados con la vía al Llano.

Para lograr lo anterior, se realiza un análisis más funcional, un acercamiento a las relaciones de localización, cantidad y distribución de los elementos urbanos que coadyuven al estudio de estos escenarios mediante una aproximación analítica que vincula escala, red y territorio; un conjunto de categorías consideradas desde la complejidad de los espacios que subyacen en la morfología urbana (Reynoso, 2006). Son sectores con procesos morfológicos que representan fenómenos espaciales particulares de expansión y fragmentación urbana en torno a la implantación de la vía al Llano y se enmarcan en elementos teóricos y metodológicos de la sintaxis espacial o sintaxis del espacio (SE).

La SE es considerada por Reynoso (2010) "como una batería de técnicas sumamente simples para cuantificar y comparar patrones de accesibilidad en espacios construidos" (p. 169); un enfoque geográfico que permite realizar el análisis urbano de estos sectores de la ciudad; un tipo de lenguaje que se comprende mediante la "lectura" completa de los cambios que se suceden en la superficie de los elementos, su forma, las conexiones y la distribución espacial que alcanzan.

La ciudad tangible tiende a manifestarse no sólo como lenguaje sino, más etnocéntricamente, como escritura en tanto arquetipo, campo y límite de toda representación y de toda forma de semiosis posible [...] una invitación a leer las ciudades o los ambientes como textos (p. 165).

Las intersecciones, las distancias entre cruces, la forma y el tamaño que tienen las áreas construidas y el centro (o la centralidad) de cada organización espacial, entre otras, pueden leerse multiescalarmente como cambios en las dinámicas sociales (colectivas o individuales) que hacen uso de los elementos urbanos. Esto permite representar unidades que tienen diferentes sentidos y jerarquías en los objetos, leer la distribución y la composición de ellos en el área analizada. En palabras de Bruno Latour (2008), los objetos "anónimos y fríos" también tienen capacidad de agencia, por lo que leer sus concatenaciones permite comprender su funcionamiento. Así, resulta importante conocer cómo

Se han desarrollado numerosos instrumentos de análisis y modelado complejo que permiten abordar las cuestiones de espacialidad y territorialidad de maneras innovadoras, aportando tanto a la comprensión interpretativa de las problemáticas como a las posibilidades de intervención (Reynoso, 2018).

Este tipo de análisis es innovador en la medida en que apropia elementos de la geometría y los utiliza geográficamente para representar y comprender los fenómenos socioespaciales (como fragmentación y expansión urbana, en este caso) no solo desde la distribución en red de distancias, sino, además, desde el grado y el comportamiento de la intensidad y en función de la accesibilidad que se da en las conexiones respecto a los elementos de infraestructura; en "ver cómo están dispuestos sus elementos en el territorio, sea de forma equitativa, equilibrada o viceversa [...] con relación a este componente urbano" (Garnica \& Jiménez Caldera, 2014). La interpretación geométrica y geográfica de esta información espacial para ver áreas de integración o áreas segregadas se hace mediante el uso de AJAX, una herramienta digital que permite el tratamiento de datos espaciales a través de la SE (Reynoso, 2010). Con esta herramienta se seleccionan y trazan los ejes del plano urbano en el área circundante a la va y la vN y sus respectivos nodos de cruce, se editan las líneas sueltas y se interconectan todos los espacios abiertos con comportamiento urbano.

Finalmente, con el uso de los elementos de SE y el programa AJAX se identifican por colores (rojo, naranja, amarillo, verdes, azules y violetas) los nodos de 
las líneas o calles más importantes, las aristas de las intersecciones entre líneas y el grado de vínculo o aislamiento de las áreas urbanas que rodean la va y la vN. Así, a partir de los diferentes grafos elaborados, se cuantifica la relación de los valores de integración de los espacios axiales (bien conectados o no) y la capacidad de movimiento entre ellos, se interpreta la sincronización y la complejidad que esconden los datos y, desde aquí, se define la existencia de algún patrón asociado a las dinámicas del sistema social (situaciones que no son fijas y que son dinamizadas por el uso y la existencia de elementos urbanos).

\section{Desarrollo temático}

\subsection{Contexto preliminar: la ciudad de Villavicencio y la vía al Llano}

La ciudad de Villavicencio es la capital del departamento del Meta (Colombia), un emplazamiento urbano configurado a lo largo de más de dos siglos de historia a través de intereses, concepciones y expectativas de múltiples actores que se expresan en el territorio (Espinel, 1989). Ubicada en la transición de la montaña a la llanura, se convierte en el principal acceso terrestre que comunica el interior del país (desde Bogotá) con los Llanos Orientales y la Orinoquia colombiana (García, 1997). Es un lugar cuya posición geográfica es estratégica para la articulación entre el noroccidente y el suroriente del país, ya que permite la entrada y la salida de carga y pasajeros, además de historias y territorialidades - como reconoce en procesos similares Beatriz Nates (2011) - (Figura 1). Una ciudad cuyos flujos con la capital de Colombia por la vía al Llano ${ }^{6}$ se intensifican, desde mediados de los años ochenta, con los beneficios de la actividad

6 Son cerca de $86 \mathrm{~km}$ desde Villavicencio a Bogotá (Coviandes, s. f.) que marcan la disposición de los elementos urbanos; una ciudad que alberga cerca del $45 \%$ de la población departamental y que se configura como el principal acceso a los Llanos Orientales de Colombia. petrolera $^{7}$ y, entrados los años noventa, por los cambios de la terciarización económica ${ }^{8}$, que hasta el año 2002 se dan por la va.

Es la principal ciudad de la Orinoquia, una región "cargada" de dicotomías políticas (inversión-corrupción, progreso-retroceso) y económicas (naturaleza-cultura, alimentos-minería, legalidad-informalidad), entre otras, las cuales dejan marcas en la periferia urbana ${ }^{9}$ (Baquero, 1986). Algunas de estas dinámicas, desde el año 2002, se conectan por la vN y son movilizadas por el túnel Misael Pastrana o túnel de Buenavista, marcando auges y retrocesos socioeconómicos relacionados con la actividad productiva, las migraciones entre lo urbano y lo no urbano, la violencia del conflicto armado y las acciones políticas del Gobierno nacional (Rausch, 2011). Elementos que configuran un crecimiento urbano en el que distintas formas y estructuras son producto de la superposición de diversas concepciones relacionadas con la llaneridad, el mercado inmobiliario, la actividad petrolera y, más recientemente, el turismo regional, que transforman la ciudad.

7 En 1986 se empieza a extraer en Arauquita (Arauca), en 1991 en Yopal (Casanare) y en 1996 en Apiay (Meta).

8 A través, por ejemplo, de las mercancías transportadas por las vías ( $5 \%$ de la carga nacional), implican que la ciudad esté en constante progreso. Para los años noventa, el municipio cuenta con 253.780 habitantes (Cámara de Comercio de ViIlavicencio, 1993) y mantiene el $45 \%$ de la población total del departamento del Meta; atrae el $80 \%$ del tráfico regional y mueve 3.500 vehículos/día (Departamento Nacional de Planeación, 1993).

9 Por la VA, expansión sobre la ladera de la montaña (años ochenta y noventa); por la VN, concentraciones urbanas en zonas de protección hídrica (años noventa y primera década del 2000); por la vía Acacías y vía Puerto López, fragmentación de asentamientos informales y redensificación con proyectos inmobiliarios (2005-2020); y finalmente, vía Catama, dispersión de asentamientos informales (2012-2020). Un conjunto de áreas que visibilizan la relación permanente y cambiante entre el interior del país y los Llanos Orientales, conectados por Villavicencio según los descrito por Diéres de Monplaisir (1943) sobre la primera imagen de la ciudad tradicional; Espine (1989), sobre la relación sociohistórica con el interior del país; Salamanca (2009), sobre la mirada a Bogotá desde la ciudad, dando la espalda a los Llanos; Rausch (2011), sobre la transformación del pueblo frontera a ciudad capital; y Romero (2021), con un análisis historiográfico de la ciudad intermedia. 


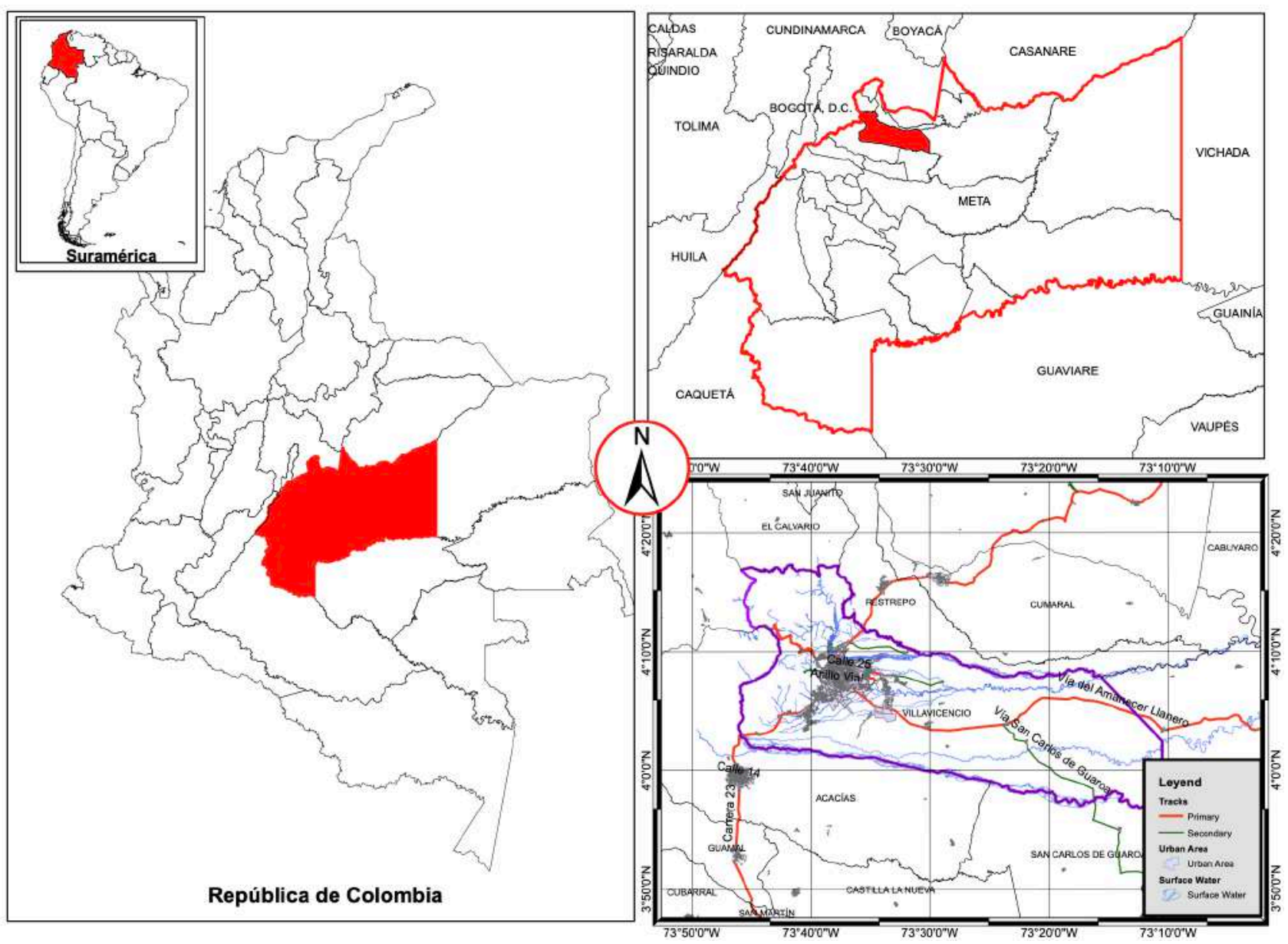

FIGURA 1. Mapa con la ubicación geográfica de Villavicencio (Colombia)

FUENTE: elaborado por Jorge Eliécer Pardo Mayorga. Universidad Santo Tomás, Sede Villavicencio, 2021.

Este contexto socioproductivo que se entremezcla con la economía del narcotráfico, la violencia política, los problemas de tierras y la pobreza rural (en aumento) es movilizado por proyectos de infraestructura vial que sirven en la articulación regional. Representa valores suficientes para reconocer como rasgo particular el aumento de la conectividad y la movilidad de las acciones del proceso político (De Mattos \& Iracheta, 2008) y la particularidad con que el poder económico homogeneiza la ciudad como nodo de articulación con Bogotá mientras pone a "gravitar" de manera desigual la periferia urbana y los territorios rurales (Massey, 2007).

Dichas concepciones producidas desde procesos políticos, económicos y sociales van dibujando diferentes formas en el plano urbano (Molotch, 1976), el cual procede, originalmente, desde el centro de la ciudad y se extiende hacia afuera como producto de la construcción de vías que articulan territorialidades cercanas, esto es, la vía al Llano ${ }^{10}$. Lo anterior es comprensible si se entiende que las vías, además de fijar áreas y perímetros, trasladan significados, abstracciones e imaginarios que se convierten en expresiones urbanas de desarrollo (Monnet, 2013). El territorio urbano se integra al orden dispuesto por la relación con el interior del país y se codifica en la cotidianidad del uso de sus vías.

Villavicencio como ciudad intermedia, ahora no distante de la modernidad, sino interconectada con Bogotá y con el resto del país "moderno" evocando progreso o desarrollo por una vía con carácter de

10 Por su primacía en la articulación Villavicencio-Bogotá, sobresale como principal accionante histórico, político y económico de la ciudad, del departamento y de los Llanos. 
autopista en un país con un marcado déficit vial; que el $84,62 \%$ de lo que se produce en el departamento del Meta tenga como destino a Bogotá $(75,26 \%$ ) y Villavicencio $(9,36 \%)$, señala la importancia pendular (hacia Bogotá, el interior del país) de la vía al Llano, para el transporte de carga y de pasajeros (Romero Novoa, 2021).

Las vías, entonces, como considera Jerôme Monnet (2006), son algo más que un objeto, se transforman en lugares desde donde se configuran diferentes territorios y se articulan múltiples procesos de apropiación espacial. Su disposición representa el imaginario y la concepción de múltiples actores a la vez que materializa las decisiones y las relaciones entre sujetos, objetos y acciones (Lefebvre, 2013). Las vías se convierten en emblemas de desarrollo y símbolos políticos de poder en diferentes escalas de la ciudad, con los cuales se crean vínculos, se definen roles, se establecen funciones, se formulan proyectos y se trazan marcas en el territorio que representan fenómenos particulares de transformación urbana (Hernández, 2017) a nivel físico y social. Así las vías, como representaciones simbólicas de lo urbano y lo no urbano, producen territorialidades enmarcadas en las relaciones con la capital del país y el desarrollo en la ciudad ${ }^{11}$ (Figura 2).

En virtud de lo anterior, es posible inferir que la vía al Llano ha tenido un papel central en diferentes marcas, como cambios en el tamaño y la forma del área urbana en los territorios que la conforman y en el relacionamiento regional con que materializa la configuración territorial de la ciudad (Vergara, 2018). Así, la expansión urbana tiene relación con la movilidad a otros lugares del país, la cual se expresa a través de las fragmentaciones que ha tenido el suelo urbano en un continuum de unidades periurbanas y, más recientemente, zonas suburbanas traslapadas con la ruralidad de Villavicencio. Los territorios, en el plano de la representación, evidencian una red fluida

11 Guardan especial correspondencia con la configuración territorial de Villavicencio en los últimos ochenta años al tomar como referencia el año 1936, cuando se materializa la interconexión terrestre por la margen izquierda del río Negro y se pone en funcionamiento, en un solo sentido, la vía al Llano. de imágenes, ideas, significados, procesos, recursos y subjetividades que registran y conforman los cambios en la ciudad (Bailly, 1979). Y, finalmente, los cambios en la estructura, en las funciones y en los usos de vías intrarregionales como la vía al Llano participan en la generación de una imagen de Villavicencio como ciudad intermedia ${ }^{12}$ ahora no distante de la modernidad, sino interconectada con Bogotá y con el resto del país "moderno" a través de la infraestructura ${ }^{13}$ atrás queda el pequeño poblado de frontera- (García, 1997; Espinel, 1989; Rausch, 2011).

La vía al Llano y las demás vías no solamente conectan a Villavicencio con ciudades y demás espacios físicos desde donde llegan y salen los flujos (Figura 3), sino que permiten relacionar a la ciudad con lugares remotos del Llano profundo a donde irradia la modernidad recibida de Bogotá o de otras ciudades del país e incluso de otros países (Montoya, 2018) a través, por ejemplo, de las mercancías transportadas por las vías. Lo anterior ubica a la ciudad en el ámbito de los territorios que no se definen o, en este caso, se configuran por su área, sino por la red de relaciones que constituyen su condición de posibilidad ${ }^{14}$. Los territorios así producidos pueden ser llamados territorios reticulares, pues responden al carácter "fluido y borroso" que Jerôme Monnet (2013) propone al estar conectados mediante redes con espacios de borde, con transformaciones que vienen evolucionando con el uso y la contracción del tiempo en la periferia (de los caminos a la autopista), que se perfeccionan mediante ideas político-culturales y del desarrollo expresadas en nuevas zonas con procesos urbanos (Rincón, 2016).

12 Ella misma evoca el progreso o desarrollo por su carácter de autopista en un país con un marcado déficit vial.

13 Se hace referencia a la interconexión que, desde la ciudad de Villavicencio, se ha realizado con la vía al Llano hacia Bogotá por la va y (ahora) por la VN, dos secciones de vía nacional que configuran el extremo norte y occidental (respectivamente) de la morfología urbana de la ciudad. Una vía que permite la movilidad de 11.000 vehículos diarios, del 70\% de arroz secano, el $21 \%$ del inventario bovino, el $70 \%$ de la carne consumida en Bogotá y el 73\% de la producción diaria de petróleo del total del país (Robledo, 2018)

14 Así mismo, mediante un conjunto de relaciones preexistentes que se despliegan sobre la escala de las relaciones; una forma diferente de entender la escala (Smith, 2002). 


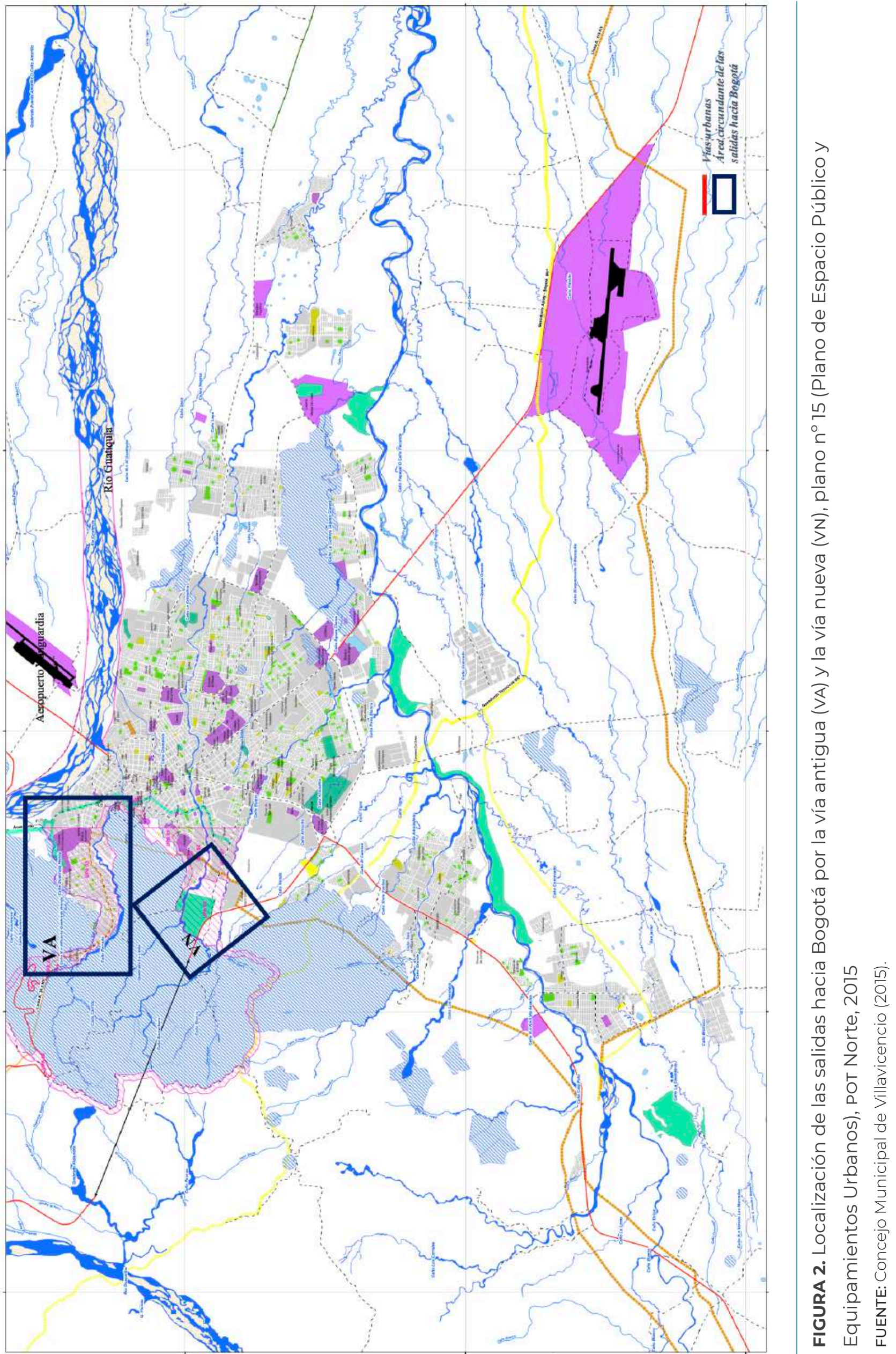



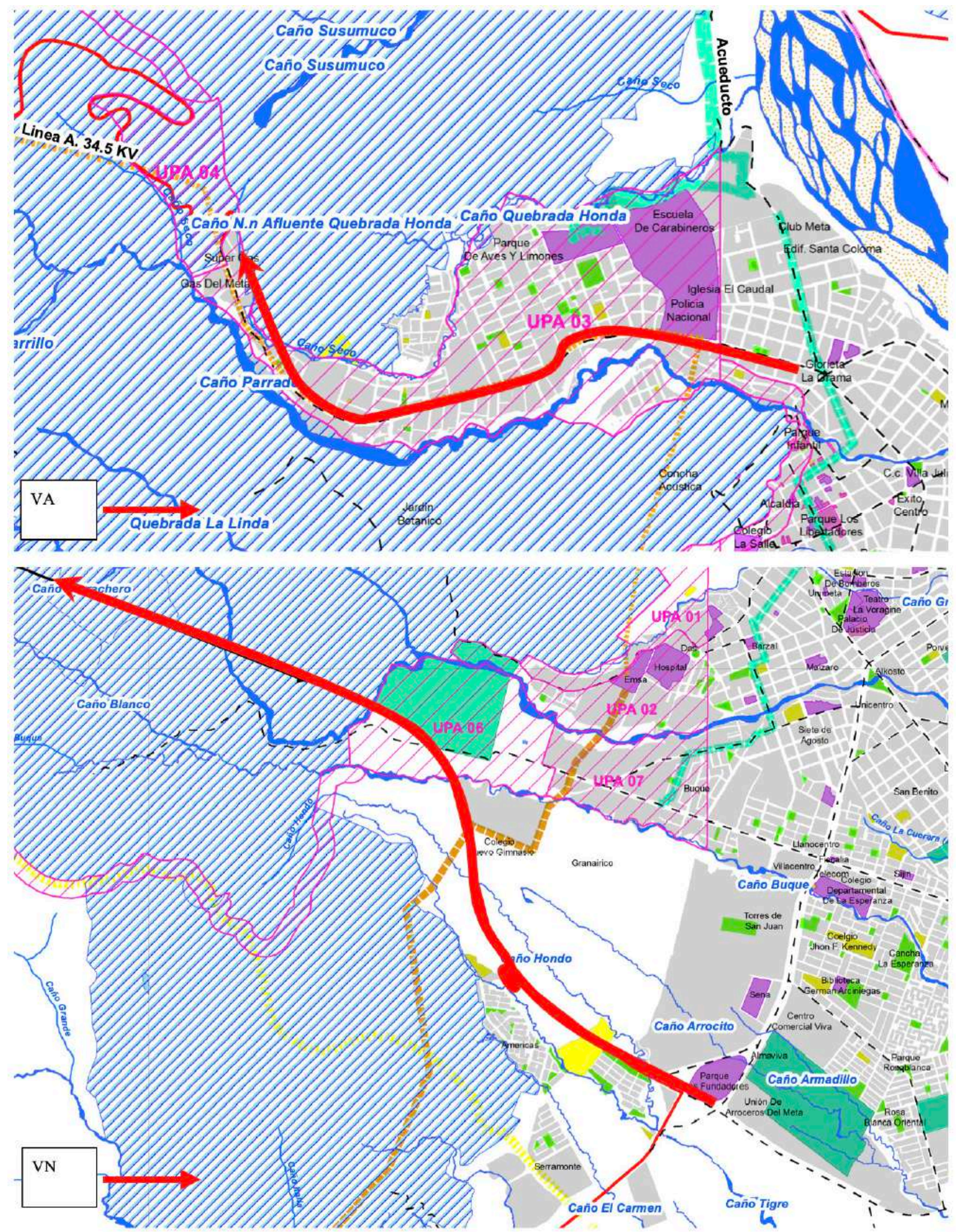

FIGURA 3. Detalles del plano n 15 (Plano de Espacio Público y Equipamientos Urbanos), salidas hacia Bogotá por la va y la vN

FUENTE: Concejo Municipal de Villavicencio (2015). 
Precisamente, se puede asumir con las figuras anteriores que las vías utilizadas para ingresar y salir del área urbana de la ciudad desde/hacia Bogotá propician dinámicas urbanas que ocupan, densifican y dan forma al lugar donde se trazan. Una geometría compleja que se aleja de la linealidad y la homogeneidad del centro urbano y que amerita una exploración más amplia y un análisis más profundo que permitan entender la lógica del territorio a través de esas condiciones geométricas.

\subsection{Desarrollo y discusión a través de elementos de sintaxis espacial urbana}

Pensar la ciudad en términos geométricos es considerar un método racional de análisis que permita comprender la complejidad de determinados modelos urbanos (Reynoso, 2018). Por ejemplo, el "orden" existente en esas dos organizaciones "caóticas" que conforman la va y la vN de la ciudad como redes que se superponen a la vía al Llano o como bordes urbanos que se traslapan a la ruralidad parte de reconocer patrones o conexiones en la integración o segregación urbana que subyace a la red conformada por las vías, las intersecciones y los respectivos nodos de cruce (Lynch, 2008). Analizar la complejidad de la estructura urbana a través de la interpretación del grado de vínculo o aislamiento que tiene la relación de los tres elementos anteriores constituye un aporte fundamental desde la sintaxis espacial ${ }^{15}$.

El análisis de complejidad en estos espacios, ubicados en dos extremos de la ciudad (la va y la vN), se da mediante el uso de los sistemas complejos, una representación espacial del nivel de integración que tiene un sistema urbano para alcanzar el mejor funcionamiento de sus elementos. A través de la geometría de sus elementos se pueden interpretar aspectos de la vida social expresados en el comportamiento y

15 Una técnica de modelado que permite interpretar la relación existente entre la red vial, las intersecciones y la estructura urbana, articuladas en una ciudad, como señala Reynoso (2009), a través de la combinación de "buenos predictores de no pocos aspectos del comportamiento social en el uso del espacio, los territorios y los lugares". la configuración urbana de la ciudad, los cuales están ocultos en el uso de las redes viales (Reynoso, 2018). Para encontrar patrones en las zonas y los alrededores de estas se utiliza el programa AJAX como herramienta digital que permite el tratamiento de los datos espaciales capturados del trazado urbano, lo que facilita comprender el uso social de la ciudad y del territorio (Bajtín, 1989, citado por Reynoso, 2010).

Al entrar a la ciudad de Villavicencio por los dos accesos mencionados - la VA, diseñada y puesta en funcionamiento desde 1936 por el sector de Buenavista, en el gobierno de Alfonso López Pumarejo; y la vN, inaugurada en el año 2002, articulada con el macroproyecto "vía al Llano" y con acceso por el túnel "Misael Pastrana Borrero" - se producen lugares con comportamiento urbano que rodean cada sector mediante diferentes dinámicas, flujos y relaciones. La geometría que tienen puede referirse a la red de distancias y la cantidad de nodos cuya topología difiere en su disposición, orden y forma, lo que permite comprender la importancia que cada elemento tiene en la medida en que varíe el número de nodos, la intensidad de las conexiones y los flujos asociados (Reynoso, 2018).

La VA, localizada sobre una ladera de montaña, con pendientes altas y trazados de vía con curvas prolongadas, configura procesos urbanos a partir del establecimiento de barrios formales producto de ejercicios municipales de planeación junto con la construcción de vivienda dispersa e informal (Figura 4). La disposición de estos elementos define la forma del emplazamiento urbano en la zona a través de manzanas con cierta cuadratura con otras de geometría tipo prebarras (áreas rectangulares con un lado menor a $80 \mathrm{~m}$ ).

La vN, ubicada en una ladera ligeramente inclinada, extensa y de superficie ondulada, tiene trazados de vía más ortogonales en un primer orden y luego, al interior de unidades residenciales, bifurcaciones que dan paso a predios y edificaciones de gran tamaño en el sector izquierdo, en el sentido hacia Bogotá, y predios con edificaciones más pequeñas en la margen derecha producto de procesos de ocupación informal en los 
años noventa (Figura 5). Una zona con cursos de agua y bosques de galería disectados longitudinalmente que definen una superficie que bordea los fragmentos residenciales.

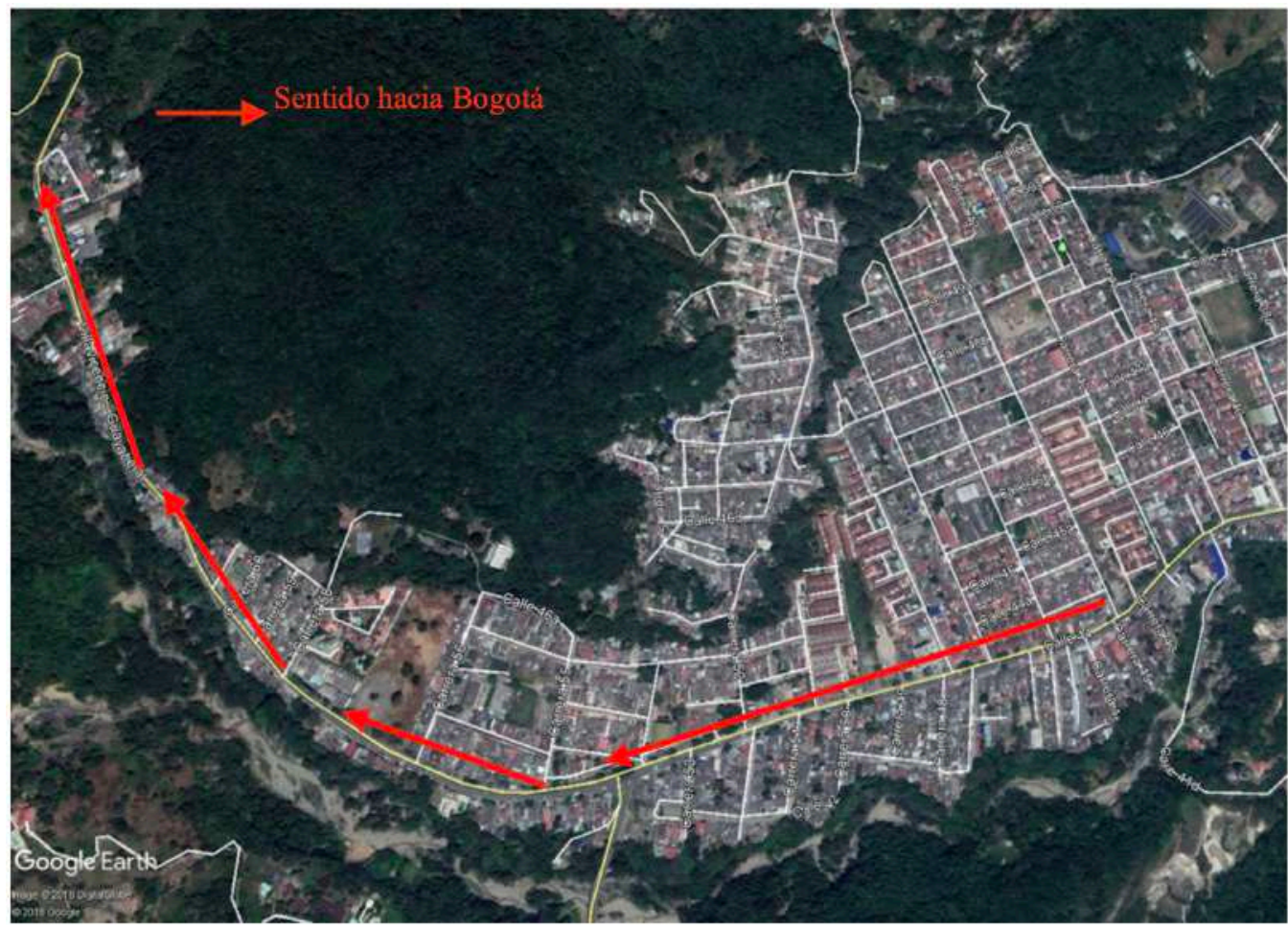

FIGURA 4. Salida hacia Bogotá por la vía antigua (VA)

FUENTE: recorte de imagen Landsat, Google Earth Pro, octubre 22 de 2018.

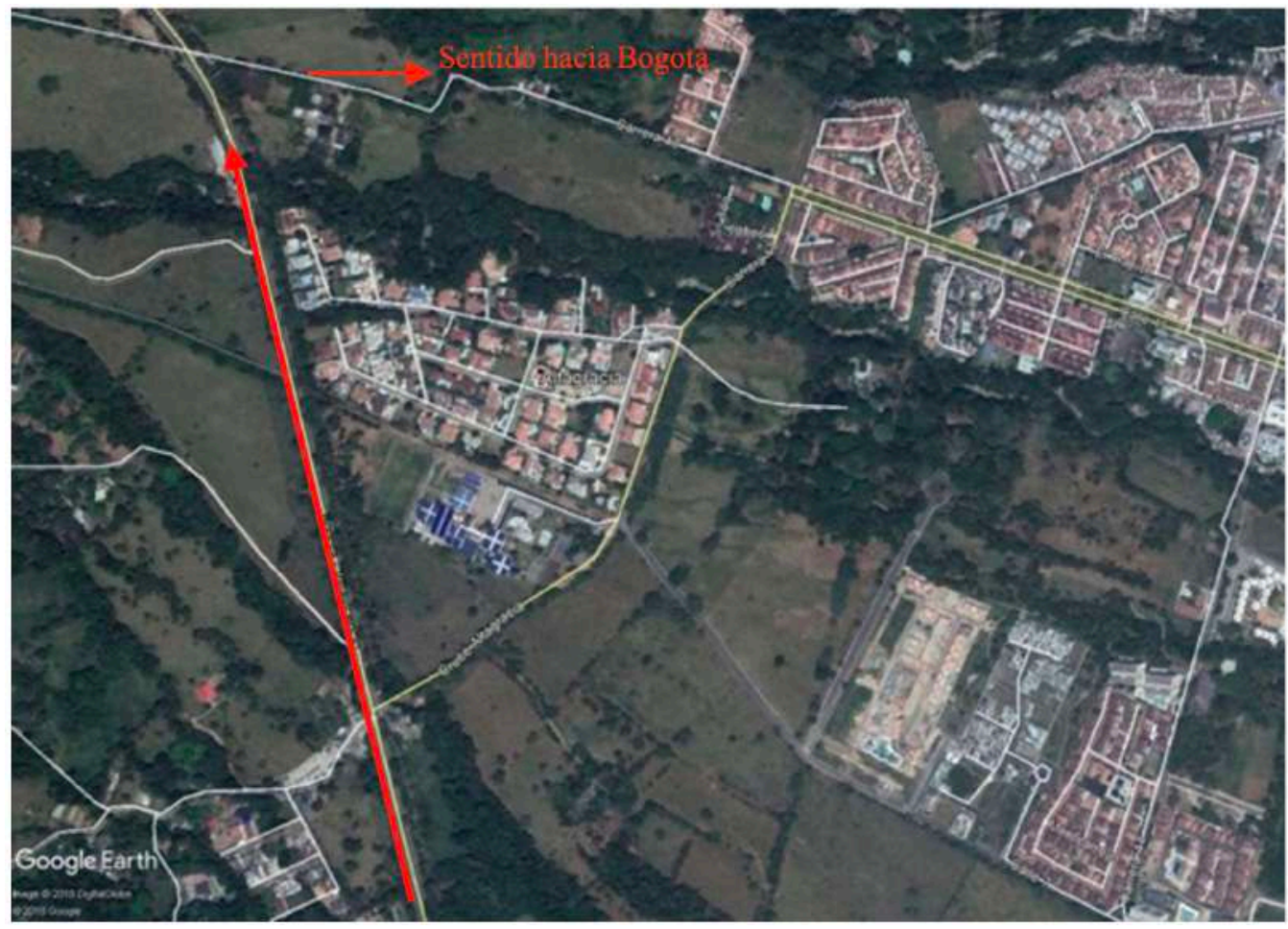

FIGURA 5. Salida hacia Bogotá por la vía nueva (VN)

FUENTE: recorte de imagen Landsat, Google Earth Pro, octubre 22 de 2018. 
Estas zonas urbanas soportadas en la vA y la vN representan estructuras que entremezclan en sus organizaciones, localizaciones y distribuciones la formalidad de la planeación y la informalidad de la construcción. Son modelos horizontales o planos geométricos que funcionan en pequeñas proporciones, en áreas fragmentadas y que ameritan ser jerarquizados para conocer su capacidad de integración o de dispersión (Batty, 2004) mediante el tratamiento de los flujos y sus rutas. Cada sector contiene un conjunto de intersecciones (nodos), de vías y calles (líneas de flujo) que representan las dinámicas de uso y funcionalidad asociadas con su ubicación.

Como calles que contienen una o más uniones, con una representación gráfica [...] más abstracta, basada en las relaciones entre las calles que a su vez se tratan como nodos $[\ldots]$ la característica clave en la sintaxis espacial es que se les da prioridad a las características lineales, como las calles, en contraste con los puntos fijos que se aproximan a las ubicaciones (Hillier, 2007).

\subsubsection{Red urbana de análisis: salida por la vía antigua}

La construcción del grafo mediante la captura en pantalla de líneas rectas sobre las vías existentes en la zona (Figura 6) permitió evidenciar el intento por mantener una ortogonalidad en el trazado urbano desde la centralidad funcional, la cual se expresa en el orden e integración que se presenta en sus manzanas y el tipo de edificaciones ciertamente homogéneas, originadas en proyectos urbanísticos de planeación municipal desde los años ochenta. Para efectos de una buena comprensión, representan una mayor morfología que busca la ortogonalidad mediante líneas en colores rojo a naranja e incluso amarillo. Ello implica mejor centralidad, uso, ocupación e integración.

Las áreas aledañas intentan mantener la secuencia ortogonal de la zona mediante pequeñas manzanas tipo prebarra (rectangulares), las cuales se alejan de la centralidad espacial mediante vías secundarias, menos rectas y prolongadas, que se adentran en la parte alta hacia el sector derecho (líneas en color verde principalmente). La articulación de estas manzanas se dispersa en la medida en que se separa de la centralidad definida. Al tener que recurrir únicamente a la salida por la VA se genera una relación "discontinua" que se entiende en edificaciones ubicadas sobre el corredor vial y una topografía de alta pendiente, coberturas vegetales y poblaciones con ocupaciones informales del suelo (detrás de ellas).

El grafo del mapa axial tiene 273 líneas y 349 nodos que da una relación de 78 líneas a uniones, con una proporción de 1,28 veces más densidad en términos de uniones a líneas (Figura 7), posiblemente debido a la cantidad de vías cortas de un solo carril y con algo de geometría que se disponen hacia el centro funcional de la zona, mientras que diversos tipos de segmentos y accesos viales de pequeñas edificaciones se incrementan al comunicar el borde urbano con la VA y se dispersan por la vía al Llano. Es un mapa axial denso que supera la cantidad de líneas por la cantidad de nodos (intersecciones y terminaciones de vía) y que, con relación al trazado y a la densidad, permite entender que la zona tiene un sesgo hacia la derecha, en donde hay mayor integración. Una idea de esta densidad se observa en la Figura 7, en donde las líneas axiales de la pantalla negra se distribuyen con las líneas en color rojo y las uniones codificadas en blanco.

La densidad de nodos percibida en la parte superior-centro de la Figura 7 representa los cambios en la linealidad de las vías, es decir, pequeñas vías con poco diseño geométrico y originadas al tiempo en que se van ocupando y edificando perimetralmente a la zona central, con marcas de dispersión urbana hacia afuera. Son procesos de construcción informal entremezclados con los de planificación municipal. Estos se repiten a través de obras secuenciales sobre la VA, cuyos usos del suelo son condicionados topográficamente por la pendiente y la cobertura vegetal. Aquí, el comportamiento edificatorio, aunque permanece, resulta variable y su dinamismo se ralentiza porque la intensidad de los flujos se traslada a la vN desde el año 2002. 


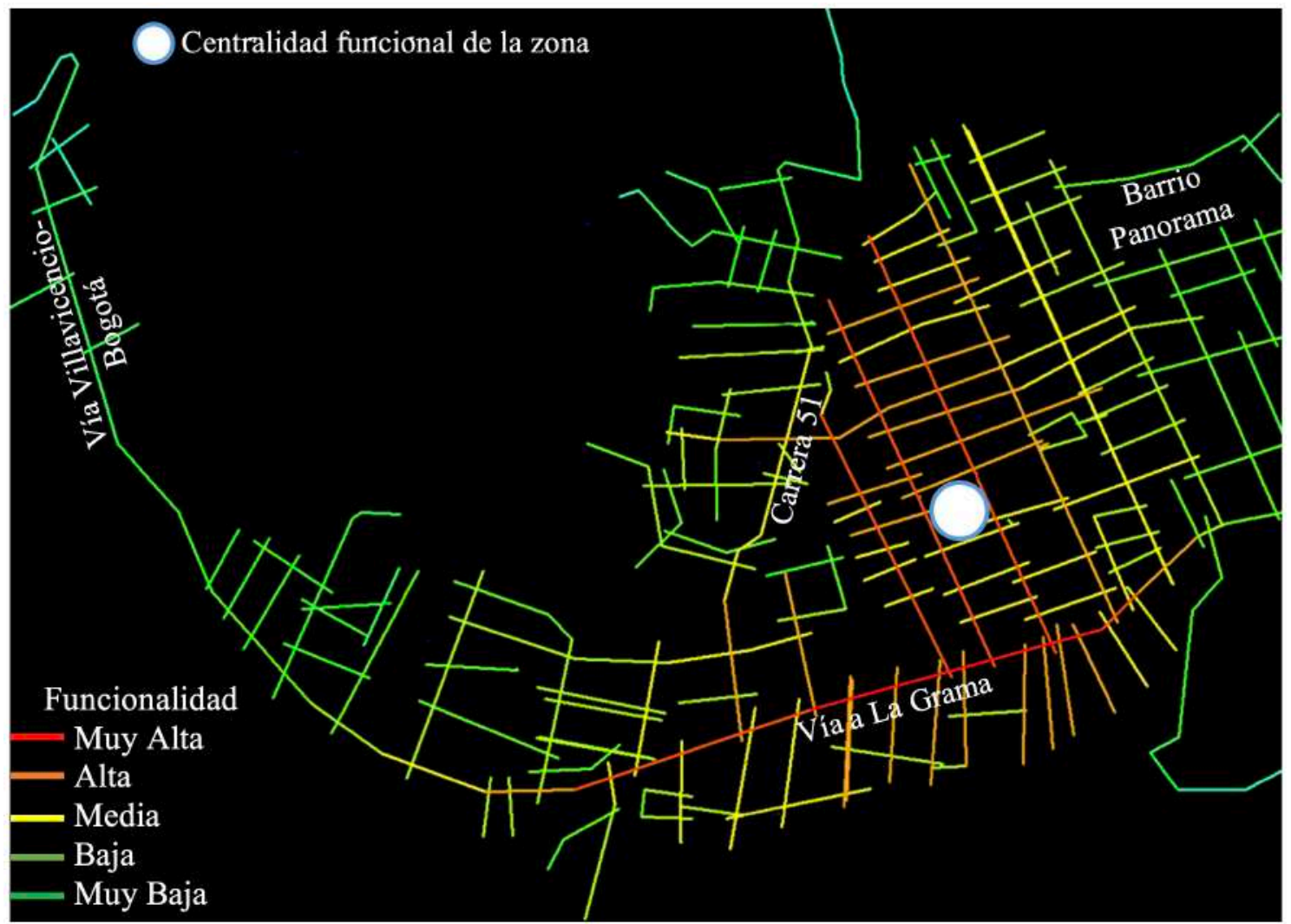

FIGURA 6. Grafo de colores de la VA

FUENTE: elaboración propia.

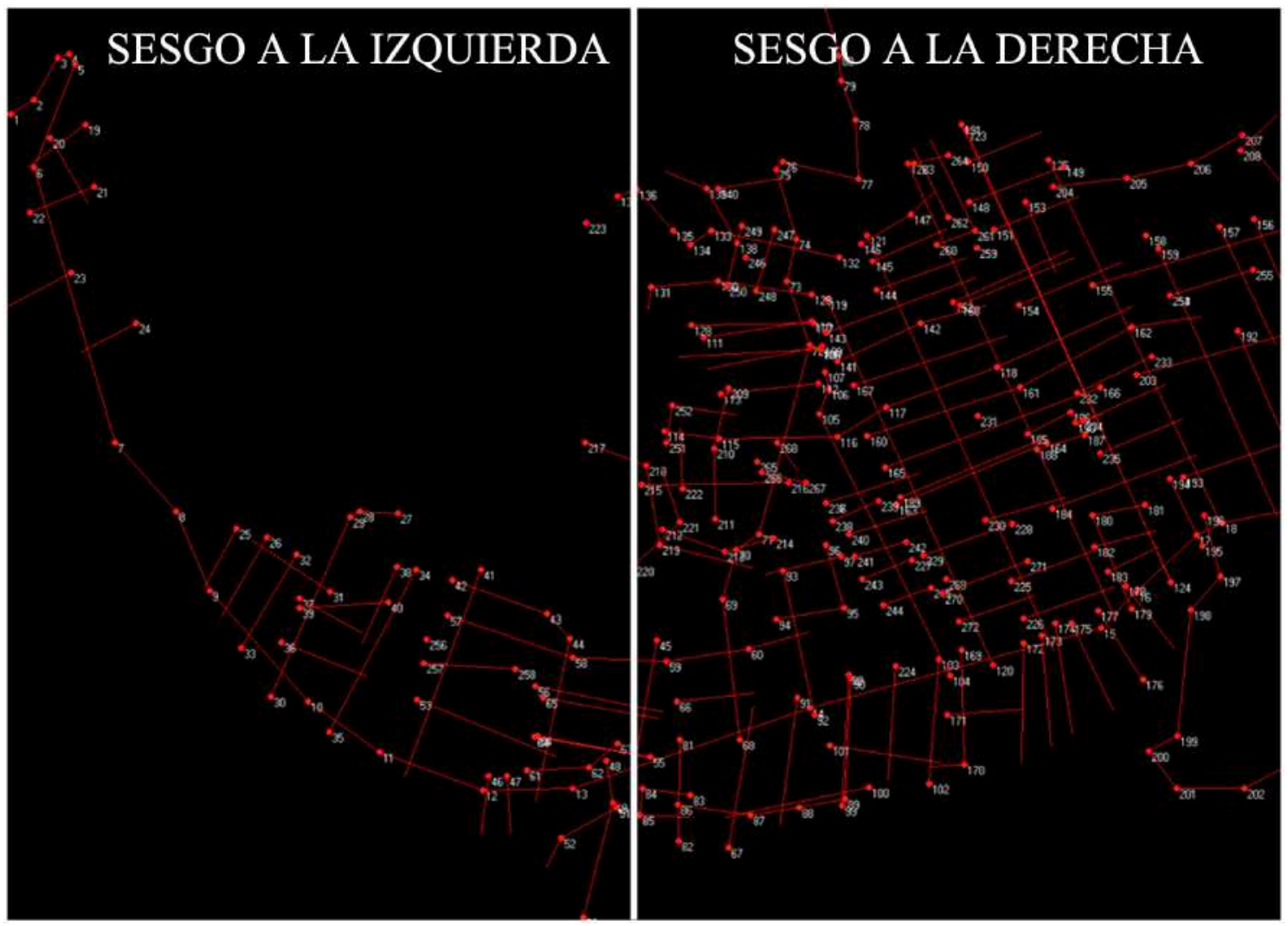

FIGURA 7. Grafo del número de líneas y número de nodos de la VA

FUENTE: elaboración propia. 
Interpretar la relación existente entre estos elementos al borde de la va (la red vial, las intersecciones y la estructura urbana) permite identificar un patrón de dispersión que, como se ha señalado, se da "de adentro hacia afuera" del centro de funcionalidad en la zona (Figura 8), el cual conforma una geometría que define la integración entre manzanas edificadas articuladas por los usos del suelo (residenciales y comerciales predominantemente) y mediante el uso de vías cortas comunicadas con la VA. Se pueden percibir aumentos en los grados de integración que se irradian hacia la periferia urbana. La funcionalidad de las intersecciones termina en áreas sin mayor integración en los bordes de la zona (en color azul marino hasta azul oscuro, que representan una menor centralidad, uso e integración; son zonas periféricas que disminuyen su funcionalidad como nodos de intersección y que, en muchos casos, representan fenómenos de dispersión).

En correspondencia con el análisis realizado, la zona urbana configurada en torno a la va se puede representar usando la forma de una "iguana", por su semejanza con esta figura. Un recurso metafórico que permite analizar el funcionamiento de la zona con aquel reptil arbóreo que tiene un cuerpo abultado donde concentra su motricidad y desde el cual salen patas cortas y cola larga para su movilidad (Figura 9). Con esta figura se puede concebir un patrón operacional en donde la centralidad de la zona agrupa e integra la mayoría de las funciones "del cuerpo"; allí se mantiene "vivo" el territorio con las diferentes espacialidades que dinamizan el comportamiento urbano desde los años ochenta. La distribución y la ocupación de las edificaciones y sus respectivos flujos hacia la parte superior-central se "sujetan" al suelo mediante una de "las patas", se fijan contra la ladera de la montaña y se van extendiendo por su borde, cuya topografía es irregular y con pendientes considerables. Finalmente, hacia la izquierda y desde la parte inferior, se desprende la "cola" longitudinalmente por la vía a Bogotá, localizando construcciones sobre la forma curvilínea y delgada de la vía; aquí "descarga" todo el flujo, la movilidad vehicular, poblacional y de servicios que se dispersa hacia los sectores de Buena Vista y Pipiral, en límites con el departamento de Cundinamarca.

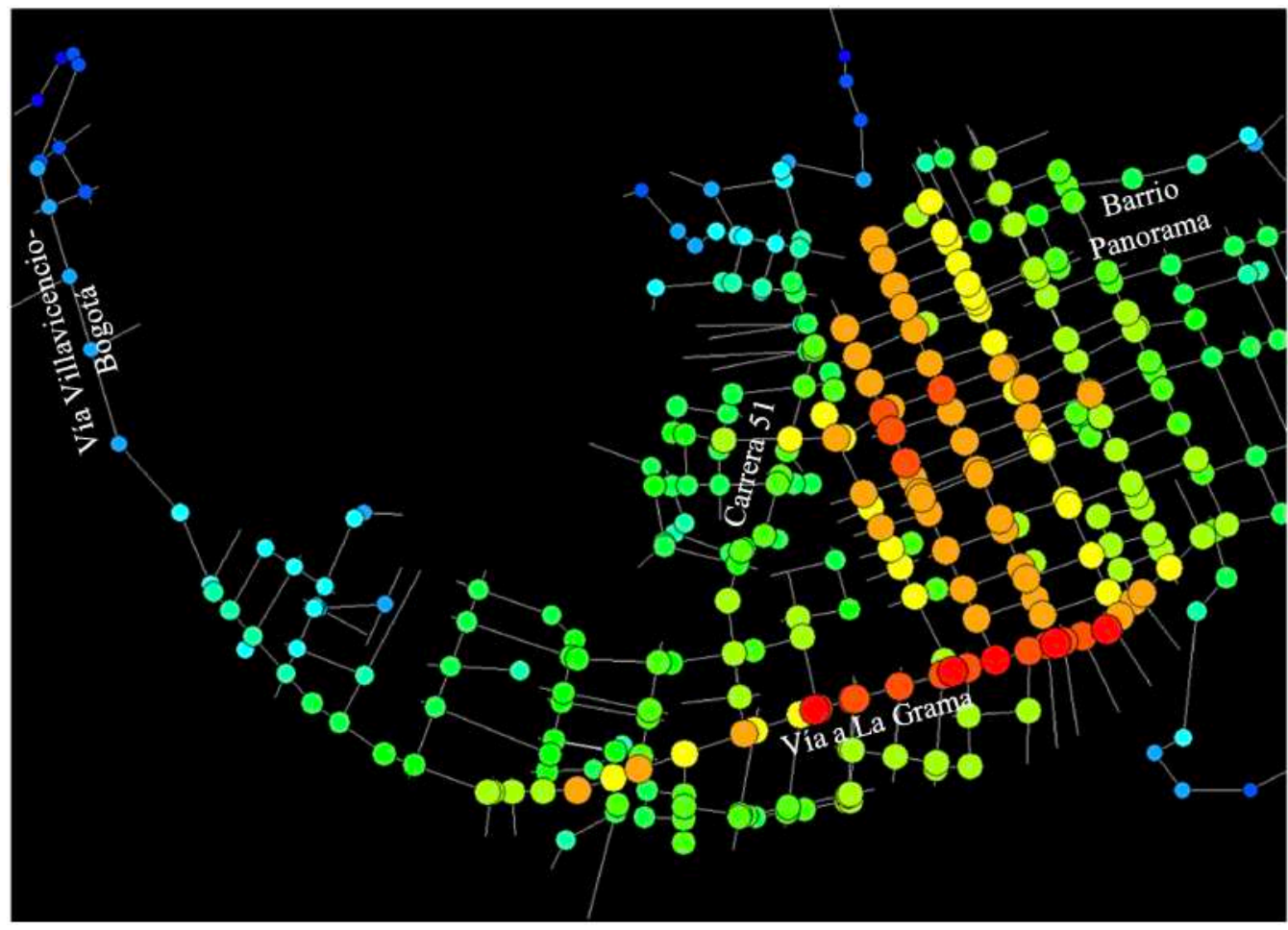

FIGURA 8. Grafo del mapa del análisis de nodos de sintaxis espacial de la va FUENTE: elaboración propia. 


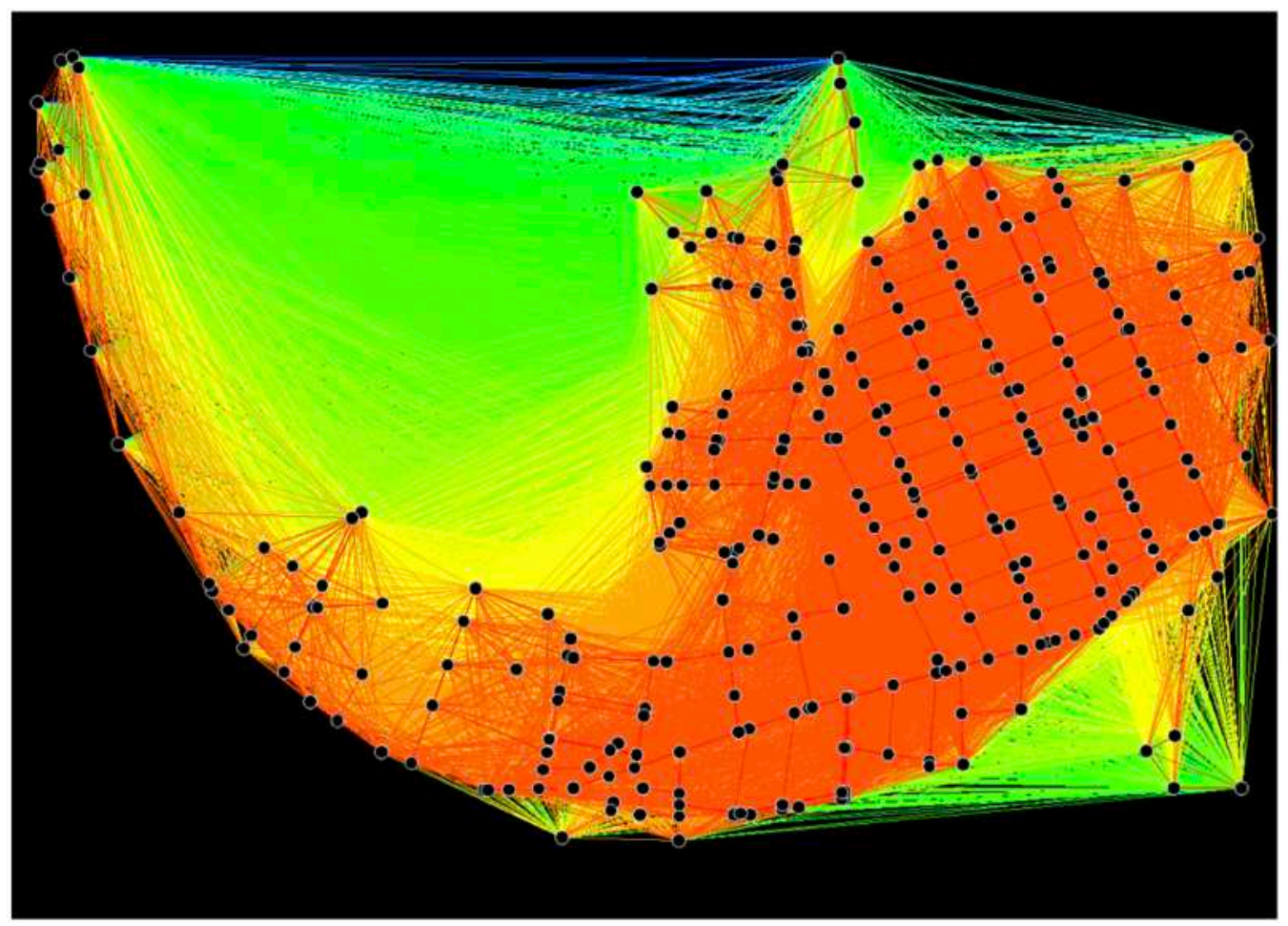

FIGURA 9. Grafo del mapa del análisis de radios de sintaxis espacial de la vA FUENTE: elaboración propia

\subsubsection{Red urbana de análisis: salida por la vía nueva}

$\mathrm{Al}$ realizar un ejercicio similar al descrito en las páginas anteriores, el grafo construido en esta sección se obtuvo mediante la captura en pantalla de líneas rectas sobre las vías existentes en la zona (Figura 10). En este se puede evidenciar una menor densidad de vías y el intento por mantener una ortogonalidad (de mayores proporciones) asociada al trazado urbano que produce la vN con intersección (parte superior izquierda de la figura) en la prolongación de la vía Circunvalación (también calle 15) (se representan mediante líneas en colores rojo a naranja e incluso amarillo que representan una mayor morfología que alcanza líneas perpendiculares; ello implica mejor centralidad, uso, ocupación e integración).

La distribución que aquí se observa es policéntrica, es decir, se identifican cuatro posibles centros sobre toda la zona; son subzonas con cierta autonomía y funcionalidad asociadas a la articulación de sus vías internas con la VN o la prolongación de la vía Circunvalación. Se presentan unidades residenciales con un tipo de edificación distinto a los que se relacionaron en la va, estas son altamente cualificadas, ocupan mayores extensiones de tierra y el orden e integración ahora es hacia adentro de cada subzona. Son proyectos urbanísticos de capital privado que se produjeron a finales de los años noventa del pasado siglo xx y comienzos del siglo xxi, los cuales definen la dinámica de urbanización en la zona con edificaciones en conjunto cerrado, espaciadas de otras urbanizaciones cercanas, con uso directo del automóvil particular y paulatina clusterización residencial-comercial hacia la ciudad (dirección suroriental).

Las subzonas señaladas propician la integración directamente con la vN y la prolongación de la vía Circunvalación al generar las intersecciones, los usos directos y las densificaciones de los flujos viales sobre sus márgenes, y, de manera importante, un patrón de "atomización" en sus vías y conformación interna, situación que presupone cierto orden como unidad residencial con la secuencia ortogonal de la zona y la 
dispersión (aceptada y formalizada) con el entorno y la vecindad que le acompaña. Cada subzona recrea, en lo posible, condiciones de centralidad propia (líneas en color verde y nodos blancos).

La articulación de estas unidades residenciales se va dispersando hacia la parte inferior (o margen izquierda) de la vN, en la medida en que se aleja de la centralidad definida por esta. Al tener que recurrir únicamente a la salida por la vN genera una relación de corredor que se entiende en las edificaciones ubicadas sobre la margen vial y el barrio contiguo, denominado Las Américas, el cual tuvo su origen y configuración a partir de la migración de poblaciones por desplazamiento rural y con ocupaciones del suelo (inicialmente) informal. Hoy en día, esta zona está reconfigurándose mediante procesos de gentrificación con condominios de casas (en la margen derecha) y periurbanización urbana de complejos residenciales (en la margen izquierda); son un conjunto de acciones de las élites urbanas ${ }^{16}$ cuyos intereses y expectativas son privilegiadas en las acciones del Estado y por la fuerza del capital asociado al mercado inmobiliario.

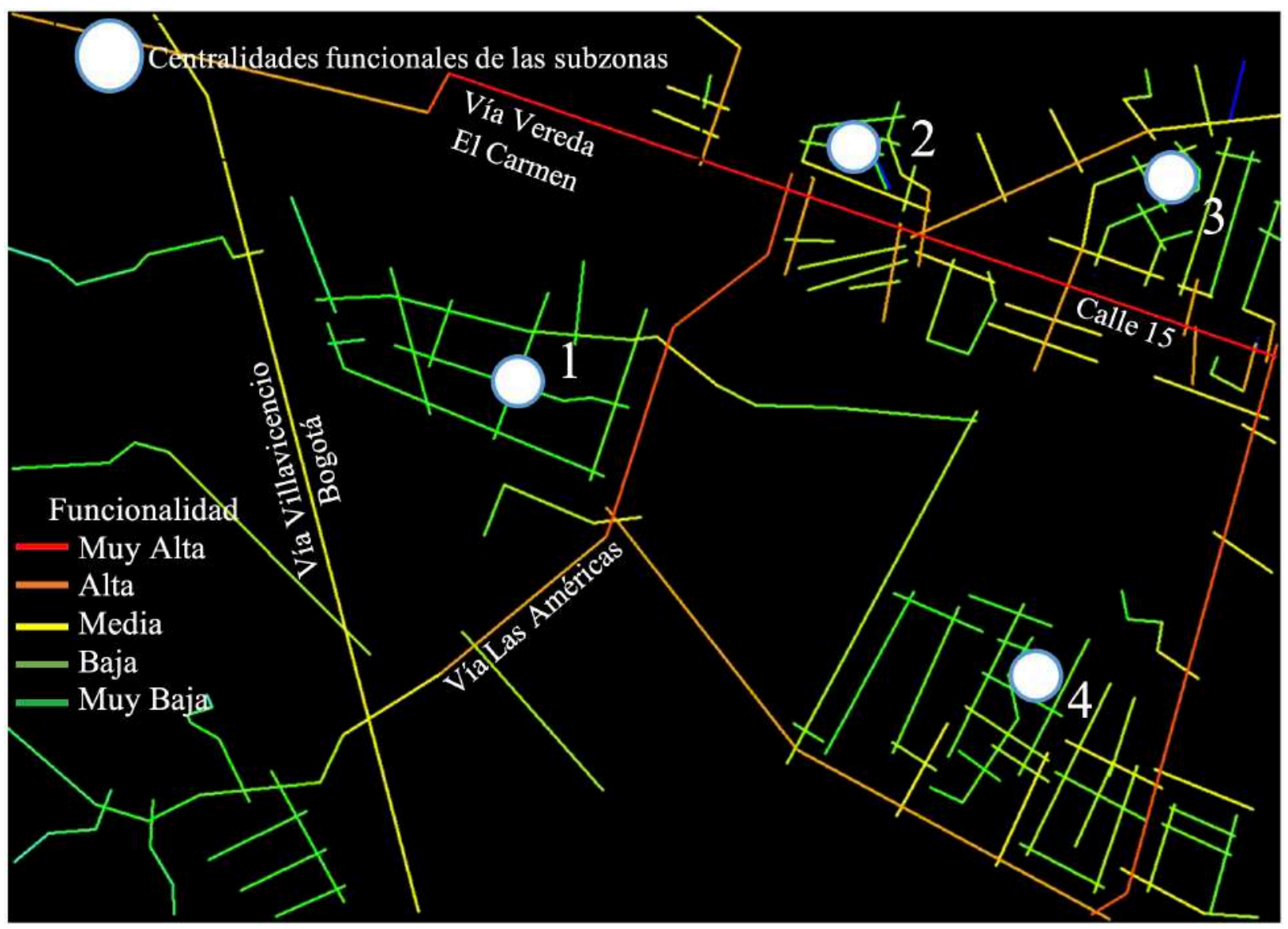

FIGURA 10. Grafo de colores de la VN

FUENTE: elaboración propia.

El grafo del mapa axial tiene 205 líneas y 212 nodos que da una relación de 97 líneas a uniones, con una proporción de 1,03 veces más denso en términos de uniones a líneas (Figura 11) que es significativamente menor que lo hallado en la va. Esta situación se puede "leer" en la disposición perimetral de la

16 Siguiendo el argumento de Lefebvre (2013), estos actores son los urbanistas, los planificadores, los proyectistas que, en su conjunto, pretenden, en concordancia con sus proyectos de ciudad, cualificar y producir nuevos espacios urbanos. 
mayor cantidad de nodos, es decir, de pequeñas vías que se ramifican al interior de cada unidad residencial y en sus alrededores. Desde allí regresan y se articulan a los nodos ubicados, discriminadamente, sobre la vN y la prolongación de la vía Circunvalación. Es un mapa axial "fragmentariamente denso" (lo que respalda la división en las cuatro subzonas definidas), el cual supera la cantidad de líneas por la cantidad de nodos en una proporción cercana a la unidad (1), lo que permite entender que, con relación al trazado, la densidad de líneas y los nodos (intersecciones y terminaciones de vía), la zona, según lo arrojado por AJAX, presume un sesgo hacia la derecha, en donde hay mayor integración. Esto resulta contrastable con lo mostrado por la Figura 11, en donde se percibe (con mayor claridad) la integración correspondiente de las subzonas 4 y 3, respectivamente, a la vía Circunvalación, con flujos directos con mayor cantidad de nodos. Esta densidad se observa en la Figura 11, en donde las líneas axiales de la pantalla negra se distribuyen con las líneas en color rojo y las uniones codificadas en blanco.
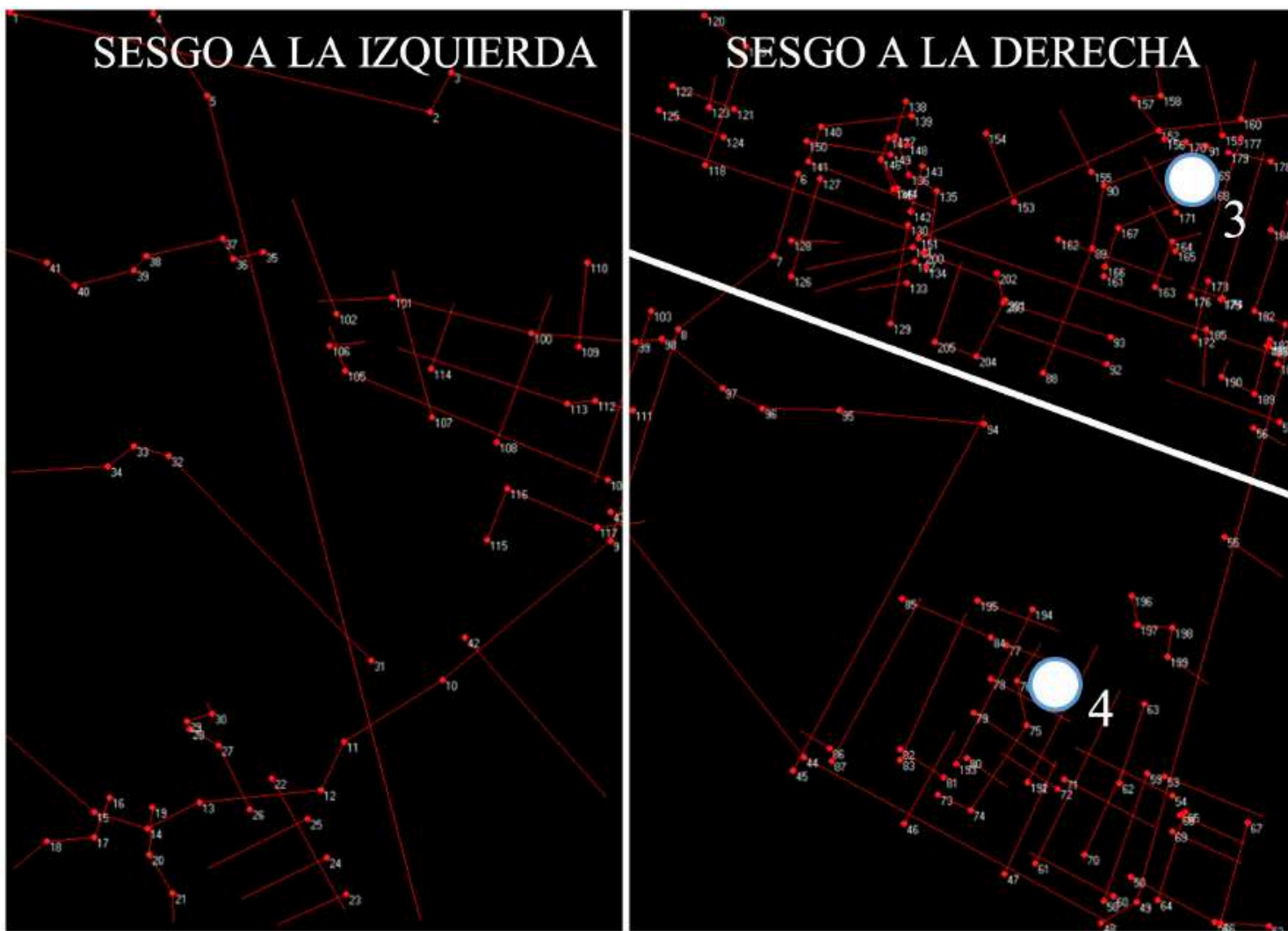

FIGURA 11. Grafo del número de líneas y número de nodos de la VN

FUENTE: elaboración propia.

La densidad de nodos ahora se puede analizar de forma diferente a lo sucedido en la vA. En la parte superior-derecha de la Figura 11 aparecen cerca de 30 nodos más que en el resto de la zona, un comportamiento que supera en un 50\% aproximadamente la distribución que se percibe en la parte inferior (derecha). Allí existen, como se ha descrito, unidades residenciales que se densifican hacia el interior de sus áreas por las vías, las cuales presentan cambios en la linealidad mediante su longitud y conectividad, es decir, pequeños accesos con un buen diseño geométrico destinados a comunicar los intersticios residenciales (hacia adentro) del perímetro de cada subzona, que pueden reconocerse como marcas de integración urbana con procesos de dispersión socioespacial. Son procesos de construcción por etapas que van ocupando 
las márgenes de las vías (vN y la extensión de la vía Circunvalación), generalmente con poblaciones que tienden a tener un alto poder adquisitivo (Nates, 2008) y que buscan retirarse del centro urbano y establecerse en perímetros cuyo acceso a la ciudad sea mínimo, además de contar con la posibilidad de salir hacia Bogotá rápidamente, sin la necesidad de integrarse al resto del área urbana.

Las relaciones que se perciben entre la red vial (local e interna), las intersecciones y la estructura urbana de la zona que rodea a la vN tienen una articulación que bien podría señalarse de dicotómica, toda vez que presentan una integración con las vías principales hacia afuera (flujos largos, nodos grandes), secundarias hacia adentro (flujos cortos, nodos pequeños) y, a su vez, un patrón de dispersión que, como se ha señalado, configura cuatro subzonas independientes entre sí (Figura 12). Quizás resulta impreciso generalizar que en ellas la dispersión socioespacial sea igual puesto que, si se "lee" con atención la Figura 10, las subzonas 4 y 3 presentan una integración un poco mayor que las subzonas 2 y 1 y conforman una geometría más integrada a la prolongación de la vía Circunvalación y la vN respectivamente. Se pueden percibir tendencialmente grados de integración que se dispersan hacia el interior de cada unidad residencial. La funcionalidad de las intersecciones se repite a lo largo de las vías señaladas en zonas de borde de la vN.

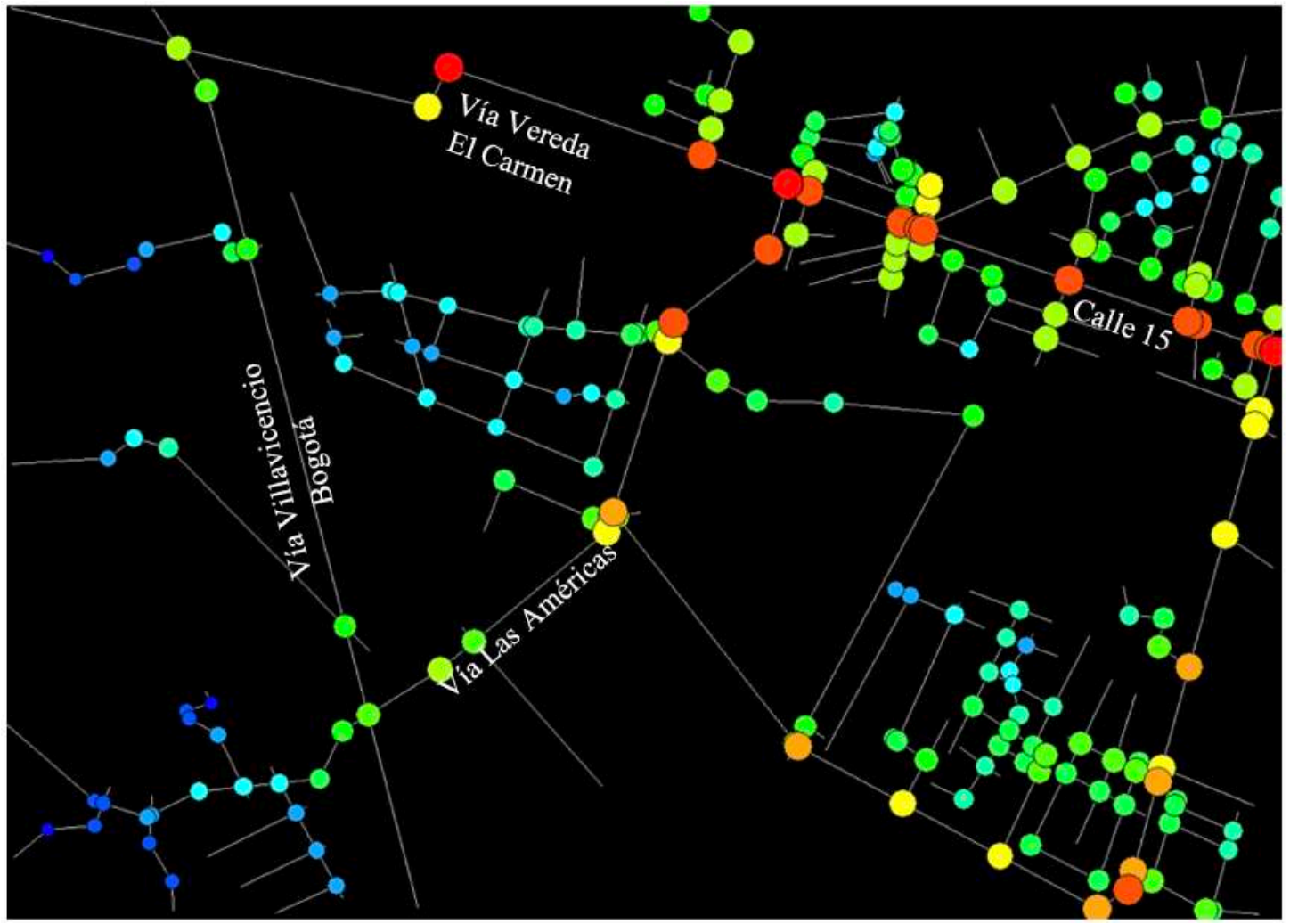

FIGURA 12. Grafo del mapa del análisis de nodos de sintaxis espacial de la VN FUENTE: elaboración propia.

NOTA 1: en color rojo hasta un verde claro los ejes que, siendo prolongaciones de la ciudad hacia la periferia occidental, soportan nuevas intersecciones con flujos vehiculares de estas zonas residenciales independientes y de alto poder adquisitivo.

NOTA 2: en color azul marino hasta azul oscuro que representan, como se ha señalado, una menor centralidad, uso e integración; son zonas periféricas que disminuyen su funcionalidad como nodos de intersección y que, en este caso, representan fenómenos de dispersión mediante condominios y conjuntos cerrados. 
En correspondencia con el análisis realizado a la zona definida por la vN, en este caso se representa mediante el uso de una figura rectangular divida por una "diagonal" de la esquina superior izquierda hacia la esquina inferior derecha (línea morada), la cual guarda cierta relación de semejanza con lo que se puede apreciar en el grafo del mapa del análisis de radios de sintaxis espacial (Figura 13). La intensidad de las líneas de color naranja permite representar la cantidad de flujos relacionados con la movilidad vehicular y la dinámica poblacional y de servicios presentes en las últimas dos décadas, la cual se dirige en dos direcciones (arista superior e inferior del triángulo naranja) hacia sectores con centros comerciales, zonas de discotecas y restaurantes (arista inferior) y hacia la vía al Llano (arista superior), empero, no se integra con las áreas urbanas circundantes (líneas de flujo naranja que bordean de arriba-abajo, verticalmente, el recuadro de la Figura 13).

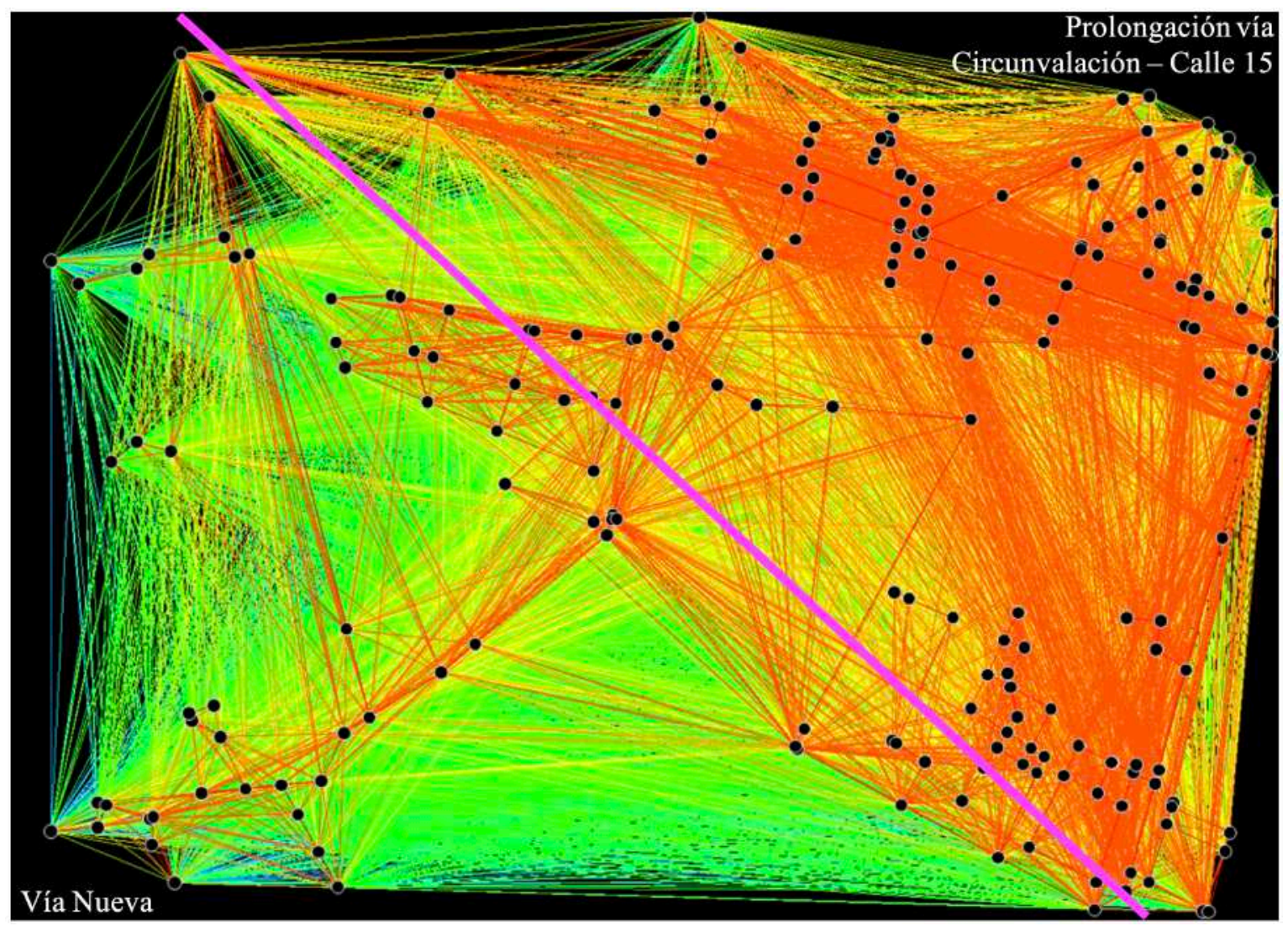

FIGURA 13. Grafo del mapa del análisis de radios de sintaxis espacial de la vN

FUENTE: elaboración propia.

En la figura anterior se puede apreciar un patrón de simetría triangular: superior, de color naranja, con mayores intensidades de los flujos, e inferior, de color verde, con algunos flujos, en donde la intensidad de los flujos con mayor integración está en la zona superior (prolongación de la vía Circunvalación), mucho más evidente y que contrasta con la menor intensidad de la zona inferior (margen izquierda de la vN), la cual mantiene un menor grado de integración con la parte superior, de dispersión. Esto hace referencia a la intensidad de los flujos debido al uso y la movilidad en las zonas de condominios cuyas rutas de acceso privado entran y salen por la vía Circunvalación. Las líneas diagonales y los diferentes nodos en la subzona 4 denotan los movimientos desde cada unidad residencial hacia el acceso que es común y de allí hacia la zona comercial o la vía hacia Bogotá. 


\section{Conclusiones}

La distribución geométrica de las vías y de sus intersecciones y la forma areolar o fragmentaria que definen los grafos producidos en los procedimientos y las técnicas enmarcadas en la sintaxis espacial (sE), aquí, mediante el uso de AJAX, permiten realizar un análisis espacial de la estructura urbana que rodea los flujos vehiculares que rodean la va y la vN de Villavicencio hacia Bogotá. En esencia, muestran patrones de repetición, remarcación y concentración en áreas con geometrías ortogonales que explican o permiten entender (con algo más que la topografía de sus elementos o la representación cartográfica de la información) la intensidad de uso y los flujos con una disposición entrecruzada y con aumento en la cantidad de los nodos. Así, por un lado, en la va se entiende la articulación a un solo centro de funcionalidad desde el que se vinculan los procesos urbanos existentes e irradian procesos residenciales dispersos que producen la disminución de nodos e intersecciones al borde. Por el otro, en la vN la representación resulta ambivalente porque tiene elementos urbanos con integraciones propias e intensidades en sus flujos producto de su disposición con condominios y conjuntos cerrados, pero, a la vez, al estar conectadas por la vía Circunvalación, incorpora dispersiones en su articulación con espacios comerciales dispuestos en su entorno (lo que se expresa en su localización periférica a la ciudad).

El análisis espacial realizado a la estructura urbana que rodea los flujos vehiculares a Villavicencio por la va y la vN permite describir los elementos físicos de la ciudad mediante el grado de vínculo y aislamiento, de relación y de distribución que tienen. Un signo de lo socioespacial que se expresa en la articulación de sus vías, sus nodos y sus intersecciones. Son relaciones funcionales que, además de localizar los elementos, permiten interpretar el uso de la infraestructura vial y la producción de nuevas articulaciones funcionales que se localizan en sectores perimetrales a través de los mapas axiales y los grafos construidos, donde cada uno muestra que la integración va más allá de las vías y se evidencia en la jerarquización de las conexiones. Esto es, la correlación espacial que subyace en las vías, los nodos y su distribución en estos dos sectores de la ciudad visibiliza relaciones entre territorios urbanos con la periferia. Una "dicotomía" urbana que se define en dos comportamientos relativos a su disposición geométrica: por la va, integración social de sus elementos desde el centro funcional de la zona y cambios en la dispersión de nodos hacia la periferia; por la vN, cuatro centros funcionales independientes, donde cada uno da cuenta de la integración por subzonas (planificada y con geometría areal) hacia adentro de sus emplazamientos y que solo se conectan con su entorno por las vías locales, de forma dispersa (con geometría longitudinal-alargada). Un fenómeno que se asocia a su diseño como unidades cerradas, aisladas de su contexto, contenedoras de un tipo de población que busca ingresar lo menos posible a la ciudad y mantener un vínculo constante con la capital del país.

El crecimiento urbano de Villavicencio desde los años ochenta por la va hacia Bogotá define un polígono ensanchado hacia el nororiente del sector (pese a las condiciones topográficas existentes: alta pendiente, suelo de piedemonte estrecho y sinusoidal). Las figuras analizadas sobre este (recortes de Google Earth Pro y grafos producidos con AJAX) materializan la centralidad funcional de la zona a través de la convergencia semiortogonal de las vías, las intersecciones y los flujos internos que conectan con la vía curvilínea hacia Bogotá. Son un conjunto de elementos que aumentan su intensidad hacia las áreas menos pendientes y desde el año 2002, por la vN, configuran una zona amplia areolar con múltiples centralidades (cuatro subzonas). Las condiciones observadas dan cuenta de una ladera con pendientes medias-bajas colindante con zonas comerciales de la ciudad, donde la ocupación (dinámicas residenciales) establece un aumento de los flujos y las interacciones sociales hacia el interior de las subzonas que mantienen un crecimiento "ordenado" o "planificado" que las integra. 


\section{Referencias}

Aliste, E. A., Díaz, A. A., \& Ther, F. R. (2015). Transformaciones territoriales y discursos del desarrollo en el área metropolitana de Concepción (Chile), 1960-2010. Atenea (Concepción), 512, 49-67.

Bailly, A. S. (1979). La percepción del espacio urbano. Institutos de Estudios de Administración Local.

Baquero, O. (1986). Departamento del Meta: historia de su integración a la nación 1536-1936. Universidad Nacional.

Batty, M. (2004). A new theory of space syntax. UCL Working Papers Series.

Bielza, V. (2011). El tema de la morfología urbana en la historia del pensamiento geográfico. Geographicalia, 59-60, 27-45.

Cámara de Comercio de Villavicencio (CGV) (1993). Indicadores económicos. Cámara de Comercio de Villavicencio.

Choay, F. \& Urrieta, S. (2009). El reino de lo urbano y la muerte de la ciudad. Andamios, 6(12), 157-187.

Concejo Municipal de Villavicencio (2015). Plan de Ordenamiento Territorial - POT Norte. https://www. concejodevillavicencio.gov.co/normograma/category/152-plan-de-ordenamiento-territorial? start $=20$

Contreras, C. (2006). Paisaje y poder político: la formación de representaciones sociales y la construcción de un puente en la ciudad de Monterrey. En D. Hiernaux-Nicolas, A. Lindón \& M. Aguilar (coord.), Lugares e imaginarios en la metrópolis (pp. 171-186). Anthropos.

Corboz, A. (2004). El territorio como palimpsesto. En Á. M. Ramos (ed.), Lo urbano en 20 autores contemporáneos (pp. 25-34). UPC.

Coviandes (s. f.). Calzada Existente. Datos Técnicos. https:// www.coviandes.com/calzada-existente

De Mattos, C. \& Iracheta, A. (2008). Globalización y territorio. Centro- $h, 2,99-110$.

Diéres de Monplaisir, M. (1943). Lo que nos contó el abuelito. Imprenta San José.

Departamento Nacional de Planeación (DNP) (1993). Carretera Bogotá-Villavicencio. [Documento MINTRANSPORTE-DNP-2654-UINF-DITRAN]. Departamento Nacional de Planeación.

Espinel, N. (1989). Villavicencio, dos siglos de historia comunera, 1740-1940. Gráficas Juan XXIII.

García, M. (1997). Un pueblo de frontera: Villavicencio 18401940. Asesores Culturales.
Garnica, R. \& Jiménez Caldera, J. (2014). La calidad de vida urbana y la dimensión físico-espacial del espacio público: aportes metodológicos para el ordenamiento territorial de Montería. Perspectiva Geográfica, 18(2), 257-280.

Hernández, G. (2017). "Renaissance" à Montpellier et "refondation" à Pereira. Invocations mythiques et conceptions du temps dans des opérations d'urbanisme en France et en Colombie. $[\mathrm{PhD}$ dissertation in Urban Planning]. École d'Urbanisme de Paris.

Hillier, B. (2007). The space is the machine: A configurational theory of architecture. UCL.

Latour, B. (2008). Reensamblar lo social: una introducción a la teoría del actor-red. Manantial.

Lefebvre, H. (2013). La producción del espacio. Capitán Swing. Lynch, K. (2008). La imagen de la ciudad. Gustavo Gili, SL.

Molotch, H. (1976). The City as a Growth Machine: Toward a Political Economy of Place. American fournal of Sociology, 82(2), 309-332. http://www.jstor.org/stable/2777096

Monnet, J. (2006). La rue et la représentation de la ville: iconographie et lieux communs à Mexico et à Los Angeles. Flux, 66-67, 8-18. https://doi.org/10.3917/ flux.066.0008.

Monnet, J. (2013). El territorio reticular. En B. N. Cruz (coord.), Enfoques y métodos en estudios territoriales (pp. 137-167). Red Internacional de Estudios sobre Territorio y Cultura, Doctorado en Estudios Territoriales, Instituto de Investigaciones en Ciencias Sociales y Humanas y Grupo de Investigación Territorialidades de la Universidad de Caldas Manizales-Colombia.

Montoya, J. W. (2018). De la ciudad hidalga a la ciudad globalizadora. Universidad Nacional de Colombia.

Nates, B. (2008). Procesos de gentrificación en lugares rururbanos: presupuestos conceptuales para estudio en Colombia. Revista de Antropología y Sociología: Virajes, 10, 253-269.

Nates, B. (2011). Soportes teóricos y etnográficos sobre conceptos de territorio. Co-herencia: revista de humanidades, $8(14), 209-229$.

Rausch, J. (2011). De pueblo de frontera a ciudad capital. La historia de Villavicencio, Colombia, desde 1842. Banco de la República; Unillanos.

Reynoso, C. (2006). Complejidad y caos: una exploración antropológica. https://www.academia.edu/53510010/Complejidad_y_Caos_Una_exploraci\%C3\%B3n_antropol\%C3\%B3gica_2006_ 
Reynoso, C. (2009, febrero 16). Sintaxis espacial. https:// www.academia.edu/58921402/Sintaxis_espacial_ T\%C3\%A9cnicas_de_an $\%$ C3\%A1lisis

Reynoso, C. (2010). Análisis y diseño de la ciudad compleja. Centro Editorial Javeriano.

Reynoso, C. (2018). Curso Escalas del Territorio. Universidad de Caldas, Doctorado en Estudios Territoriales, Manizales.

Rincón, P. (2016). Ejes de infraestructura vial y dinámicas urbano-regionales. El caso del corredor Bogotá-Bucaramanga, Colombia (1950-2005). Sociedad y Economía, 31, 33-70.

Robledo, J. E. (2018). Lo que usted no sabe de la vía Bogotá-Villavicencio. https://jorgerobledo.com/lo-que-usted-nosabe-de-la-via-bogota-villavicencio/
Romero Novoa, J. A. (2021). La fragmentación urbana como marca de la ciudad intermedia: análisis multitemporal de la transformación urbana de Villavicencio (Colombia), entre 1936-2018. Ponencia presentada en el $2^{\circ}$ Encuentro Latinoamericano de Estudios del Rururbano (ELER).

Salamanca, J. (2017). Villavicencio: la ciudad de las dos caras. Credencial Historia, no 231. http://www.banrepcultural.org/biblioteca-virtual/credencial-historia/ numero-231/villavicencio-la-ciudad-de-las-dos-caras

Santos, M. (2000). La naturaleza del espacio. Ariel.

Smith, N. (2002). Geografia, diferencia y políticas de escala. Terra Livre, 2(19), 127-146.

Vergara, A. F. (2018, abril 5). Las escalas, las infografias y los imaginarios. [Notas de clase]. Doctorado en Estudios Territoriales, Universidad de Caldas. 